\title{
Identifying the arsenic-safe aquifers of the Ganges Delta: some insights into sustainable aquifer management
}

\author{
M. Chakraborty ${ }^{1}$, A. Mukherjee ${ }^{1,2,3}$, K.M. Ahmed ${ }^{4}$, P. Bhattacharya ${ }^{5}$ \& A.E. Fryar $^{6}$ \\ ${ }^{1}$ Department of Geology and Geophysics, Indian IIT Kharagpur, Kharagpur, West Bengal, India \\ ${ }^{2}$ School of Environmental Science and Engineering, IIT Kharagpur, Kharagpur, West Bengal, India \\ ${ }^{3}$ Applied Policy Advisory to Hydrogeosciences Group, IIT Kharagpur, Kharagpur, West Bengal, India \\ ${ }^{4}$ Department of Geology, University of Dhaka, Curzon Hall Campus, Dhaka, Bangladesh \\ ${ }^{5}$ KTH-International Groundwater Arsenic Research Group, Department of Sustainable Development, \\ Environmental Science and Engineering, KTH Royal Institute of Technology, Stockholm, Sweden \\ ${ }^{6}$ Department of Earth and Environmental Sciences, University of Kentucky, Lexington, KY, USA
}

\begin{abstract}
The widespread health impacts on millions of people from consumption of arsenic (As) contaminated groundwater of the Ganges delta necessitate an effort to locate As-safe aquifer zones and to develop a sustainable aquifer management policy. We look into the aquifer geometries, sediment characteristics and groundwater As concentrations to develop an understanding of the factors that inhibit As invasion/mobilization within the As-safe aquifers. However, the sustainability of the present-day safe aquifer is at risk due to the heavy groundwater pumping for irrigation and thus, promoting water conserving agricultural practices is extremely vital. We suggest that, formulating a sustainable As mitigation plan should also involve the non-scientific communities such as the local tubewell drillers and farmers for widespread implementation of the plan.
\end{abstract}

\section{INTRODUCTION}

Groundwater has been the main source of drinking and irrigation water for the inhabitants of the Ganges delta plains, since early 1970s. However, over the years, widespread occurrence of toxic levels of arsenic (As) in groundwater has been detected in the Ganges delta aquifers (Ahmed et al., 2004). Presently, about 60 million people living in the delta are at risk from consumption of high levels of As in drinking water (Chakraborti et al., 2009; Hossain et al., 2015).

In order to protect the fundamental human need to access safe drinking water, several mitigation efforts have been undertaken in the past, but with limited success (Hossain et al., 2015). Such efforts have revealed that installing hand-pump tubewells in Assafe aquifers is the most successful mitigation option, both in terms of community acceptance and costs involved. Hence, targeting As-safe aquifers is key to providing a sustainable mitigation plan for yielding low-As, potable drinking water.

Delineating As-safe aquifers involves a highresolution investigation of the aquifer architecture and sediment characteristics as well as the groundwater chemistry, flow dynamics and abstraction patterns. However, a large-scale implementation of this knowledge base in providing As-safe groundwater also requires formulation of simple tools and techniques for easy identification of such As-safe aquifers by the nonscientific community, e.g., the tube well construction planners and the drillers (Hossain et al., 2015).
The sustainability of the current safe aquifers may also be endangered by the heavy groundwater abstraction rates within the delta plains. Deep irrigational pumping may contaminate the low-As deeper aquifers by promoting enhanced inflow of As-rich groundwater from the shallow contaminated aquifers (Mukherjee et al., 2011). Hence, the long-term success of As mitigation programs depends on planning and implementation of sustainable groundwater abstraction policies to protect the currently safe aquifers against As invasion/mobilization in future.

The transboundary nature of the Ganges delta aquifer demands participation from both India and Bangladesh to uphold the policies of such Asmitigation programs as an effort to provide safe drinking water to the inhabitants of the delta.

\subsection{The study area}

The Ganges delta forms a triangular lobe, being bounded by the Indian craton to its west, the main Ganges River to its north and east and the Bay of Bengal to the south (Fig. 1).

\subsection{Materials and methods}

This study involves development of a hydrostratigraphic model in RockWorks 15 (RockWare, USA) using $\sim 2500$ lithologs from the study area (collected from West Bengal Public Health Engineering Department (WBPHED) and Directorate of Public Health 


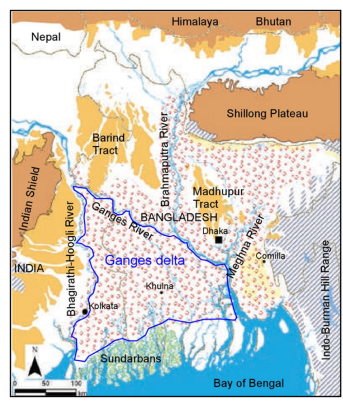

Figure 1. Map showing the study area (bordered by blue). Area with red dots marks the As-affected zone (modified from Burgess et al. (2010)).

Engineering (DPHE), Bangladesh) along with the analysis of groundwater As data.

\section{RESULTS AND DISCUSSION}

The hydrostratigraphic model shows the presence of multiple semi-connected aquifers separated by aquitards of varying thickness and extent in most parts of the delta; although, such interlayered geometry is especially well-developed to the south. These clay inter-layers hinder connectivity between aquifer units and act as a natural barrier against inflow of As or DOC from shallower depths. However, mostly towards the north, there are thick sequences of aquifer sands without sizeable clay inter-layers, resulting in free mixing of shallow As-rich waters with the relatively uncontaminated deeper groundwater (Ahmed et al., 2004). Hence, delineation of site-specific aquifer geometry is crucial to the identification of potential As-safe aquifers in an area.

The sediment color of the aquifers varies from blackish and greyish, to whitish to yellowish, reddish and brownish, being indicative of the redox status of the aquifers (Hossain et al., 2014). While the reduced grey/black sand aquifers usually have high As content, mainly due to reductive dissolution of iron hydroxides, the oxidized brown/yellow/red sand aquifers show lower As levels. Thus, sediment color may be used as one of the proxies to groundwater As content within the aquifers. However, such inferences must be integrated with an understanding of the aquifer geometry and recharge pattern.

The sustainability of the currently safe aquifers against invasion of As or DOC under future pumping conditions depends upon the pumping rates, depth of abstraction, the aquifer geometry and adsorption capacity of sediments. Although the discontinuous clay layers hinder the drawdown of DOC and As-rich water from above, the gaps in these impermeable layers allow such infiltration, under the enhanced vertical hydraulic gradient caused by irrigational pumping. Thus, deep irrigational pumping might eventually lead to large-scale contamination of the safe-water resources at depths, and hence must not be practiced.

\section{CONCLUSION}

Understanding the aquifer behaviors is key to the formulation of an effective As mitigation plan. A holistic understanding of the both the regional and sitespecific aquifer geometry and characteristics (e.g., redox states), groundwater chemistry, flow dynamics and abstraction patterns is needed to identify the As-safe and sustainable aquifer zones.

Developing simple techniques to identify As-safe aquifers (i.e., sediment color, presence/absence of clay caps), followed by involving and training the local tubewell construction planners and drillers is crucial for large-scale implementation of the As-mitigation plan. Efficient use of groundwater in irrigation and water conserving agricultural practices should also be widely promoted among the farmers.

\section{ACKNOWLEDGEMENTS}

We acknowledge West Bengal Public Health Engineering Department (WBPHED) and Directorate of Public Health Engineering (DPHE), Bangladesh for providing some of the data for this study. We also acknowledge the Swedish International Development Cooperation Agency (Sida) for the financial assistance (Contribution 75000854).

\section{REFERENCES}

Ahmed, K.M., Bhattacharya, P., Hasan, M.A., Akhter, S.H., Alam, S.M.M., Bhuyian, M.A.H., Imam, M.B., Khan, A.A. \& Sracek, O. 2004. Arsenic contamination in groundwater of alluvial aquifers in Bangladesh: An overview. Appl. Geochem. 19(2): 181-200.

Burgess, W.G., Hoque, M.A., Michael, H.A., Voss, C.J., Breit, G.N. \& Ahmed, K.M. 2010. Vulnerability of deep groundwater in the Bengal aquifer system to contamination by arsenic. Nat. Geosci. 3 (2): 83-87.

Chakraborti, D., Das, B., Rahman, M.M., Chowdhury, U.K., Biswas, B., Goswami, A.B., Nayak, B., Pal, A., Sengupta, M.K., Ahamed, S., Hossain, A., Basu, G., Roychowdhury, T. \& Das, D. 2009. Status of groundwater arsenic contamination in the state of West Bengal, India: a 20-year study report. Mol. Nutr. Food Res. 53 (5): 542-541.

Hossain, M., Bhattacharya, P., Frape, S.K., Jacks, G., Islam, M.M., Rahman, M.M., Hasan, M.A. \& Ahmed, K.M. 2014. Sediment color tool for targeting arsenic-safe aquifers for the installation of shallow drinking water tubewells. Sci. Total Environ. 493: 615-625.

Hossain, M., Rahman, S.N, Bhattacharya, P., Jacks, G., Saha, R. \& Rahman M. 2015. Sustainability of arsenic mitigation interventions - an evaluation of different alternative safe drinking water options provided in Matlab, an arsenic hot spot in Bangladesh. Front. Environ. Sci. 3 (30): 1-15.

Mukherjee, A., Fryar, A., Scanlon, B., Bhattacharya, P. \& Bhattacharya, A. 2011. Elevated arsenic in deeper groundwater of the western Bengal basin, India: extent and controls from regional to local scale. Appl. Geochem. 26(4): 600-613. 